\title{
Relationships at work - why do they matter so much?
}

\author{
Tui McKeown and Oluremi B. Ayoko \\ Associate Professor, Outgoing Editor in Chief, JMO; Associate Professor, Incoming Editor in Chief, JMO
}

Our second issue of JMO for 2020 takes a deep dive into the workplace to explore how and why our relationships at work can matter so much. Often it is the people who make or break a job for us - getting on with those we work with impacts on our happiness in not just work but in our wider life as well as on our physical and mental health. While building meaningful relationships within the workplace is very important to us - we also know there is a dark side. We explore this continuum in the eight papers presented here.

We begin with the 'light side' and a paper by Kathryn Owler and Rachel Morrison that delivers on a promise they made to us back in their 2015 publication with us to delve deeper into the notion of fun at work. In 'I always have fun at work': How 'remarkable workers' employ agency and control in order to enjoy themselves. Rather than seeing the organisation as the 'provider' of fun, this paper takes a delightfully novel approach and places the individual as the focus. This examination of the capacity of individual workers to regulate their own experience of fun seeks to "inspire both individual workers and organisations to adopt an agentic outlook in the workplace, implementing strategies that enhance employee control." We hope that it does and that it begins with you!

Looking at work and relationships differently is also a theme in our second paper but here authors Michael Tews, Kathryn Stafford and Philip Jolly take us into the world of tattoos. Here their research looks at 'An unintended consequence? Examining the relationship between visible tattoos and unwanted sexual attention' to question whether the increasing popularity of tattoos may be creating an unintended and adverse impact on employees. Focusing on sexual harassment in the restaurant and retail industries, employees, the results are disturbing and certainly provide an interesting iteration of the individual versus organisational roles noted in our first paper

The tension between individual responsibility and the organisation is made explicit in our third paper. Here authors Qingguo Zhai, Saifang Wang and Helen Weadon look at 'Thriving at work as a mediator of the relationship between workplace support and life satisfaction'. They find clear evidence of the value of workplace support positively affecting thriving at work and that thriving at work is then positively related to life satisfaction. What is interesting in the study is the role that supervisor support and co-worker support play in thriving at work. This takes us to a deeper perspective into the relationships of work and offers a more nuanced view as to how both individuals (as employees, supervisors and co-workers), and organizations play a role in improving individuals' thriving at work and their life satisfaction.

Our next paper takes us into a deeper and more focused view. Yin-Mei Huang's examination of 'The relationship between networking behavior and promotability: The moderating effect of political skill' provides us with insight into how individuals use of networking at both the career and community levels lead to supervisory promotability evaluations. The study draws in the notion of political skill and not surprisingly, the results provide for interesting implications!

While the notion of political skill may have both positive and negative connotations, our next paper moves us explicitly to the 'dark side'. Cheng-Chen Lin and Fong-Yi Lai's paper is titled 'The mechanism and boundary conditions of the relationship between customer incivility and service 
quality' and uses a sample from the restaurant industry in Taiwan to investigate how customers acting rudely (to put it bluntly), affects levels of service the restaurant employees deliver. If anyone needs the prompt to treat restaurant staff well, the finding that high levels of surface acting occur when .... (yes, you need to read this one to find out!)

The importance of incivility as a response to negative workplace relationships is developed in a difference direction in our sixth paper. Here the team of Dirk De Clercq Dirk De Clercq, Inam Ul Haq, Muhammad Umer Azeem (who have published with us a number of times), examine 'The relationship between workplace incivility and depersonalization towards co-workers: Roles of job-related anxiety, gender, and education'. The ongoing impact of employees' exposure to workplace incivility is to depersonalize their co-workers - the question is why? This study finds that individuals felt anxious about their jobs and this was particularly so for male and higher-educated employees. The authors draw on notions such as disrespect and dignity and reveal how they operate as powerful individual factors.

The next paper by Yevhen Baranchenko, Yizhong Xie, Zhibin Lin, Marco Chi Keung Lau, and Jie Ma continues the relationship thread by examining the nexus between employability and turnover intention. Employability is a challenge in contemporary organisations especially given technological advances and the related fear that robots and artificial intelligence may replace humans in the workplace. The study moves work in this area forward by differentiating between internal and external employability and their respective impact on turnover intention and in the context of perceived organizational support and career orientation. The authors find that external employability positively influenced turnover intention, but internal employability negatively influenced turnover intention. Positive organizational support also has a positive moderating effect only on the relationship between external employability and turnover intention and for employees with disengaged career orientation, external employability exerts a strong impact on turnover intention. Altogether, these findings have significant implications for you as a researcher and or HRM practitioner.

From employability to entrepreneur orientation and cultural intelligence, our final paper in this issue by Faruk Sahin and Sait Gürbüz examines the relationship between entrepreneurial orientation and international performance in the face of cultural intelligence. This article extends cultural intelligence literature by theorising that a critical factor in the implementation of entrepreneurial orientation is the top managers' cultural intelligence. The results suggest that the extent of entrepreneurial orientation is related to a firm's international performance and is contingent on the levels of three dimensions of cultural intelligence (metacognitive, cognitive, and motivational). Also, as theorised, increase in all cultural intelligence dimensions of top managers is associated with stronger entrepreneurial orientation and international performance. If you are an entrepreneur at heart (researcher or practitioner), this is a must read article!

The eight articles we have selected for this $2^{\text {nd }}$ edition of JMO for 2020 has covered a range of topics and issues in the relationships of work. What we have found in each of the studies presented here is that workplace relationships have a direct effect on our actions, attitudes and behaviours at work. Workplace relationships are individually based and are uniquely interpersonal - but they also have group and team aspects. They are not just important, they can help or hinder employees and organization and they are often at the very heart of the challenges and rewards of management.

Cite this article: McKeown T, Ayoko OB (2020). Relationships at work - why do they matter so much? Journal of Management \& Organization 26, 133-134. https://doi.org/10.1017/jmo.2020.3 